\title{
Comparative Analysis of Surgical outcome and Complications of DCR and DCR with Tube Intubation in Young Patients with Chronic Dacryocystitis.
}

\author{
Priyanka ${ }^{1}$, Shekhar Chaudhary ${ }^{2}$, Arshad $^{3}$, Sushma ${ }^{3}$ \\ ${ }^{1}$ Assistant Professor, ${ }^{2}$ Professor \& HOD, ${ }^{3}$ Junior Resident, Dept. of Ophthalmology, Patna Medical College \& Hospital, Patna, Bihar.
}

\section{Abstract}

Background: Purpose: To study surgical outcome and complications of DCR and DCR with tube intubation in young patient with chronic dacryocystitis. Subjects and Methods: A hospital based prospective randomized comparative clinical study conducted at Eye department Patna Medical College from 01.02.2018 to 30.01.2019 was done after taking approval of ethical committee of the institute. A total of 42 patients were recruited for the study and were randomly divided into two groups. Group A was DCR patients without intubation and group B was with intubation. The success rate, complications of each group was studied. Results: In group A, mean age of the patients was 26.6(+/- 4) with range of 21-34 years. In group B, mean age were 23.85 (+/-3.89) with range of 22-35 years. There were 9 males (21.40\%) and 12 females $(28.50 \%)$ in group A and 10 males $(23.80 \%)$ and 11 females $(26.10 \%)$ in Group B. Common intraoperative complications during surgery were bleeding from incision site due to angular vein injury, bleeding from nasal mucosa and nasal mucosal tearing. Success rate was $57.14 \%$ in non-intubated cases and $90.4 \%$ in intubated cases which was statistically significant. Fisher exact test statistics value ( $\mathrm{p}=0.0325)$ '. Conclusion: DCR with tube intubation may cause better success rate as compared to the DCR without tube intubation in young patients. However, larger population of this age group is needed to be studied for more longer period of time for a definitive conclusion.

Keywords: DCR, Dacrocystitis.

Corresponding Author: Priyanka, Assistant Professor, Dept. of Ophthalmology, Patna Medical College \& Hospital, Patna, Bihar.

Received: February 2019

Accepted: February 2019

\section{Introduction}

Epiphora is the main presenting symptom of chronic dacryocystitis, and is a common ophthalmic problem. The traditional approach to distal NLD block is external dacryocystorhinostomy (DCR). It was first performed by Adei Toti in 1904. Suturing of lacrimal sac and nasal mucosa was suggested by Ohm. Use of silicon tube with DCR is useful in some cases as was advocated by Older. External DCR is still gold standard procedure for NLD block.

\section{Subjects and Methods}

A hospital based prospective randomized comparative clinical study conducted at Eye department Patna Medical College from 1-02.2018 t0 30.01.2019 was done after taking approval of ethical committee of the institute. A total of 42 patients were recruited for the study and were randomly divided into two groups. Group A was DCR patients without intubation and group B was with intubation.

Inclusion criteria of patients between 20 to 35 year of age with primary NLD obstruction with or without mucocele were included in the study. Patients with secondary NLD obstruction, failed DCR, canalicular and punctual occlusions, nasal mucosal pathology were excluded from the study. Informed consent was taken from each patient.

All selected patients were examined under slit lamp. Anterior segment examination along with lacrimal drainage system was done. Regurgitation on pressure over lacrimal Sac (ROPLAS), lacrimal irrigation, fundus examination were done in all cases. ENT consultation to rule out gross nasal pathologies was done. Medical fitness for surgery with lab investigation for viral marker was done. These patients were randomly divided into two groups, Group A with 21 patients underwent plain DCR while group B consisted of 21 patients with DCR with tube intubation.

In Group A, surgery was done under local anesthesia. A curvilinear incision of $10-12 \mathrm{~mm}$ was made $3 \mathrm{~mm}$ away from medical canthus corresponding to the anterior lacrimal crest. After blunt dissection of orbicular oculi the lacrimal sac and posterior wall of the sac was excised and anterior flap was secured with 6/o vicryl sutures. A bony window of $10 \mathrm{X} 12 \mathrm{~mm}$ diameter was created taking care to preserve the nasal mucosa.

In group $\mathrm{A}, \mathrm{U}$ shaped incision was made in the nasal mucosa and sac to create a single flap which was anastomosed with each other. The posterior flap of both sac 
$\&$ mucosa were excised. The anastomosis was suspended to the orbicularis muscle to prevent sagging and wound was closed with 3 interrupted $6 / 0$ vicryl sutures. The skin incision was closed in layers. A firm pressure dressing was done after antibiotic ointment application.

In group B, after creating, opening in normal mucosa and sac, silicon tube was passed from lower and upper puncta respectfully. A bolster was used to secure the tube in the nasal cavity. The anastomosis of sac \& normal mucosa was done and wound closed in layer.

Postoperatively, all patients were given normal and local antibiotic and nasal decongestant for one week. Follow up of all cases were done on day 1 , day 10 and then after 1 month, 3 month \& 6 month from the day of surgery, Skin sutures were removed on 10th postoperative day. Any complications like infections, wound gaping, discharge etc. were looked for at each visit. Tightness and mobility of the tube was checked.

The surgical success was defined by patency of lacrimal drainage system on irrigation at final follow-up. Non patency was considered as failure.

Statistical analysis was done with the collected results.

\section{Results}

Table 1: Intraoperative Complications.
\begin{tabular}{|l|l|l|l|l|}
\hline Complications & \multicolumn{2}{|l|}{$\begin{array}{l}\text { Group A DCR } \\
\text { without intubation } \\
(\mathbf{n = 2 1})\end{array}$} & \multicolumn{2}{l|}{$\begin{array}{l}\text { Group B DCR with } \\
\text { intubation (n=21) }\end{array}$} \\
\cline { 2 - 5 } & Number & Percentage & Number & Percentage \\
\hline Uneventful & 14 & $66 \%$ & 15 & $57.1 \%$ \\
\hline $\begin{array}{l}\text { Bleeding from } \\
\text { incision site }\end{array}$ & 2 & $9.5 \%$ & 1 & $4.76 \%$ \\
\hline $\begin{array}{l}\text { Bleeding from } \\
\text { nasal mucosa }\end{array}$ & 2 & $9.5 \%$ & 3 & $14.2 \%$ \\
\hline $\begin{array}{l}\text { Nasal mucosa } \\
\text { tearing }\end{array}$ & 3 & $14.28 \%$ & 2 & $9.5 \%$ \\
\hline
\end{tabular}

In group A mean age of the patients was 26.6(+/- 4) with range of 21-34 years. In group B, mean age were $23.85(+/-$ $3.89)$ with range of $22-35$ years. The age difference between two groups $(\mathrm{t}=0.85 \mathrm{P}=0.39)$ was not significant.

There were 9 males $(21.40 \%)$ and 12 females $(28.50 \%)$ in group A and 10 males $(23.80 \%)$ and 11 females $(26.10 \%)$ in Group B.

\begin{tabular}{|l|l|l|l|l|}
\hline Table 2: Success rate in terms of patency and recurrence \\
\hline \multirow{2}{*}{ Items } & \multicolumn{2}{|c|}{$\begin{array}{c}\text { DCR without intubation } \\
(\mathbf{n = 2 1})\end{array}$} & $\begin{array}{r}\text { DCR with intubation } \\
(\mathbf{n = 2 1})\end{array}$ \\
\cline { 2 - 5 } & Number & Percentage & Number & Percentage \\
\hline Success rate & 12 & $57.14 \%$ & 19 & $90.4 \%$ \\
\hline $\begin{array}{l}\text { Recurrance } \\
\text { of epiphora }\end{array}$ & 9 & $42.85 \%$ & 2 & $9.52 \%$ \\
\hline
\end{tabular}

Common intraoperative complications during surgery were bleeding from incision site due to angular vein injury, bleeding from nasal mucosa and nasal mucosal tearing.
Success rate was $57.14 \%$ in non intubated cases and $90.4 \%$ in intubated cases which was stasistically significant. Fisher exact test statistics value $(\mathrm{p}=0.0325)$

Average duration was 48 minutes for DCR without intubation and 58 minutes for DCR with intubation.

\section{Discussion}

Nasolacrimal duct obstruction was more common in females. In our study, total number of females was 23(76.1\%). According to Duke Elder, the incidence of dacryocystitis in female is $75 \%$ to $80 \%$.

Bleeding from nasal mucosa and nasal mucosal tearing were most common complication in our study. Adrvani et al reported bleeding from incision site as most common compication $(13 \%)$ in their cases.

The duration of DCR with and without tube intubations was 58 minutes and 48 minutes respectively i.e. 10 minutes difference.

Our success rate was $90.4 \%$ in intubated case and $57.14 \%$ in non-intubated cases. The difference is statistically significant.

It has been reported that strong expression of nasal mucosal heat shock protein 47 leads to the induction of fibrosis and scar tissue.

In vivo and in vitro studies have revealed that bone fracture heal more quickly in younger individuals than older patients due to superior osteoblastic activity (Linberg et al).

Above study revealed that DCR with tube intubation may cause better success rate as compared to the DCR without tube intubation in young patients. However, larger population of this age group is needed to be studied for longer period of time for a definitive conclusion.

\section{Conclusion}

DCR with tube intubation may cause better success rate as compared to the DCR without tube intubation in young patients. However, larger population of this age group is needed to be studied for more longer period of time for a definitive conclusion.

\section{References}

1. Duke Elder Sed, System of ophthalmology part II. 2nd ed. LondonHenery Kimpton publisher ; $1974: 568: 718$

2. Mirza Sab, Sheikh ZDA, Aziz M, External DCR with silicon tube intubations. Pak 3 - ophthalmic 2002; 16, 90 - 3

3. Mc. Wen DR Surgical treatment of dacryocystistis AORN J 1997; 268-70. 
Copyright: () the author(s), 2019. It is an open-access article distributed under the terms of the Creative Commons Attribution License (CC BY 4.0), which permits authors to retain ownership of the copyright for their content, and allow anyone to download, reuse, reprint, modify, distribute and/or copy the content as long as the original authors and source are cited.

How to cite this article: Priyanka, Chaudhary S, Arshad, Sushma. Comparative Analysis of Surgical outcome and Complications of DCR and DCR with Tube Intubation in Young Patients with Chronic Dacryocystitis. Asian J. Med. Res. 2019;8(1):OT10-OT12.

DOI: dx.doi.org/10.21276/ajmr.2019.8.1.OT3

Source of Support: Nil, Conflict of Interest: None declared. 